\title{
1. \\ INTELEKTUALAC: GLASINE O SUBJEKTU (DVANAEST MARGINALIJA, A TRINAESTA JE UMJESTO ZAKLJUČKA)
}

\section{Vjeran Zuppa}

UDK: $316.344 .32: 32$

Sažetak: Pjesnik Simonid je u Ksenofontovom spisu Hijeront ili o tiraninu prvi koji u grčkoj filozofiji raspravlja s vladarom o pitanju koje mu je ovaj "u dokolici" postavio: "kako da popravi svoju vladavinu”. Prvi je, naime, koji nije filozof, a ulazi u raspru dotle rezerviranu samo za dijalog filozofa i vladara. Ulazeći u tu raspru ovaj pjesnik se pojavljuje, kaže Kojève, kao stanoviti posrednik među njima. Kao intelektualac. Onaj koji jeziku moći nastoji posredovati govor mišljenja. Pojavljuje se, dakle, kao subjekt posredovanja. Radi, danas bi se reklo, na "propusnosti” jednoga diskursa u drugi. U postmodernim vremenima sa subjektom vrlo loše stoji. Jedni filozofi najavljuju njegov nestanak i smrt. Drugi njegovu "slabost". To da više nema što reći. Ukratko: da više ništa ne nudi. Filozofi su danas, uglavnom postfilozofije. Biografije intelektualaca, pak, u jednome su isto što i u onih daleko ranijih. One su glasine o subjektu. Da ga ima, a ne da nije. Da njegova smrt nikome nije laka. Da mu je slabost jača strana...

Ključne riječi: tiranin, pjesnik, filozof, intelektualac, majstor diskursa, majstor vladanja, posrednik, coagitare

\section{marginalija Prva}

U akle: kad "obojica nađoše vremena za dokolicu”, pjesnik Simonid i tiranin Hijeront upustili su se u razgovor o prirodi tiranijske vladavine. ${ }^{1}$ Pjesnik Simonid postavlja mu o njoj niz pitanja, ali i Hijeront mnoga upućuje njemu. Štoviše, on govori Simonidu i o mukama samoga vladanja. Kaže, na primjer, da tirani "poznaju ljude neustrašive, vješte i pravedne", no da mu se "čini najvećom bijedom priznavati da ima ljudi od vrijednosti, a biti prisiljen služiti se drugima”. ${ }^{2}$

1 Ksenofont, "Hijeront ili o tiraninu". Usp. Leo Strauss, O tiraniji - Ksenofont, Hijeront ili o tiraninu-Alexandre KoJÈve, Tiranija i mudrost, Zagreb 1980., 7-23.

2 Isto, 15. 
Ovaj raison d'être tiranijske vladavine: biti prisiljen služiti se drugima, a ne vrijednimastare koliko i sam politički život - prisutan je do danas, gdje je nezaobilazni modus operandi u totalitarnim sustavima, partitokracijama, ali i u takozvanim "mladim" demokracijama. Taj ključan conditio: "biti prisiljen", nikada nije mijenjao svoje qua non, već jedino one oblike vlasti koji ga trebaju da njime "operiraju", a pri tome ga tek različito tumače.

U sokratičkome dijalogu o prirodi tiranijske vlasti i potrebi da se nju ne samo "popravi" nego i usavrši, pjesnik Simonid - a kojega Hijeront smatra "učenim čovjekom" - nudi ovomu vladaru ne samo niz savjeta nego i ciljni prijedlog. "Učeni čovjek" Simonid, naime, ima i svoju "teoriju" o idealnoj tiraniji koju nudi Hijerontu.

Alexandre Kojève posebno upozorava na to da je Simonid "u zbilji samo pjesnik", pa i njegovu "teorijsku" poziciju prvenstveno označava kao poetsko-vizionarsku, snovitu i utopijsku. ${ }^{3} \mathrm{~K}$ tomu: i Sokratov je usud, odnosno to što je ovaj filozof doživio pod demokracijom, mogao utjecati na osobitu formu diskursa $a^{4}$ kojim pjesnik Simonid govori $o$ tiraniji $u$ tiraniji, a pred tiraninom. Tako "učeni čovjek" Simonid na samoj "sceni"s ovoga dijaloga uzima - u odnosu na Hijeronta - i ulogu "učenika", a tada, iz njihove igre s pozicijama, on na tiranina često apelira.

Hijeront mu dopušta da govori. Pritom i on mijenja uloge. Ništa više od toga ne poduzima, a na kraju njihova razgovora pušta pjesnika da ode u miru.

\section{marginalija Druga}

Simonid je, dakle, "učen čovjek". On nije filozof, već je pjesnik. Nema, a niti ikako "priprema" diskurs za filozofiju. Njegov "teorijski" diskurs jest "učen", ali nije i do-učen. U njemu, naime, stalno sudjeluje, katkad i sasvim difuzno, onaj uznemirujući govor fikcije (vizionarske, oniričke, utopijske), koji unutar prepleta još raznih drugih diskurzivnih svojstava ovdje upućuje i na sasvim posebnu diskurznu osobinu: onu autorstva.

Pjesnik Simonid, taj stranac u Hijerontovu gradu, učeni je čovjek čiji je teorijski diskurs - autorski, a pri tome mu nije samo izvedba dijaloga, već mu je i čitavi proizvodni postav - akterski. Na primjer: u ulozi Lukavca, ne bi li i njome izbjegao raznim neugodnostima u razgovoru s tiraninom, zastupao je i to da je život u tiraniji "poželjniji" od običnoga. Gnuša se vulgarnoga mišljenja puka o tiraniji. Međutim, on ima i jake zamjedbe o njoj. Tu Simonid traži mogućnost da izađe iz uloge učenika te da preuzme ulogu Učitelja i ponudi Hijerontu svoju osnovnu Ideju o "prosvijećenoj” tiraniji kao obliku vladavine kojim bi se patologija tiranijske vlasti mogla izbjeći ili, makar, jako ublažiti radikalnom terapijom.

3 Isto, 134.

4 Strauss, primjerice, ističe intelektualnu dovitljivost i diskursnu opreznost kojom Simonid u svojoj kritici tiranije izbjegava riječi sloboda, zakon. Isto, 50.

5 Upravo Strauss oprostoruje tekst ovoga dijaloga dramskim pojmovima scena, likovi, uloge. Isto,43 i dalje.

6 Heidegger u svome spisu Parmenides tim radnim pojmom: trajne "pripreme” $z a$ filozofiju, upozorava kao na osnovnu upućenost samoga grčkog jezika. Usp. Martin Heidegger, "Parmenides”, Gesamtausgabe, knj. 54, Frankfurt am Main 1982., 132 i dalje.

7 Na ovo konstitutivno svojstvo, jedno među raznim "dimenzijama diskursa”, posebno upozorava Foucault u svome predavanju (1970.) na Collège de France Poredak govora (L'ordre du discours, Pariz 1971.). 


\section{marginalija Treća}

Strauss u Simonidovu "teorijskom" diskursu nalazi onu licentiu autorstva koja ovomu diskursu omogućuje i jednu njegovu sasvim posebnu vrijednost. K tomu Strauss naglašava i performativnost učenoga Simonida unutar dijaloške scene s Hijerontom. Kojève, ${ }^{8}$ pak, posebno analizira taj lik i naročito pri tome ističe sasvim specifični "posrednički" položaj pjesnika Simonida. Budući da se u Ksenofontovu tekstu Hijeront ili o tiraninu - prvi put u grčkoj filozofiji - dijalog o problemima vlasti i vladanja ne vodi između filozofa i vladara, već između vladara i pjesnika, važno pitanje koje Kojève postavlja glasilo bi: Što je $t u$ Simonid? Što tu radi taj pjesnik? Taj "učeni čovjek". Kojève za njega kaže da je on "tipični intelektualac".

Budući da je "čin vladanja unutar već formirane Države, u svom izvoru, potpuno diskurzivan, tako onaj koji je postao majstorom diskursa, ili 'dijalektike', može postati i majstorom vladanja". ${ }^{\circ}$ Nedvojbeno je da bi filozof, jer je najveći "majstor diskursa", mogao biti i vrstan "majstor vladanja". Dakako, "ne samo zbog veće dijalektičke spretnosti"10 od ma koga drugoga. Ima u njega još sposobnosti koje bi mu to omogućavale, ali bi tada svoju najveću Vrlinu, vrlinu Mudrosti (=Filozofije), koja od filozofa zahtjeva da joj "posveti svoj život" (Hegel) i koja mu osigurava ekskluzivni autoritet među sugrađanima, ozbiljno ugrozio.

Riječ je o tome da se radi o takvoj vrlini "koja mu uzima sve njegovo vrijeme", baš "kao što vladanje državom uzima sve vrijeme jednoga čovjeka". ${ }^{11}$ Tako bi - ako se prihvati državništva - zato jer više ne bi imao onoga svoga vremena, slijedile i "teoretske nesigurnosti i moralni sukobi” koji bi ga mogli dramatično i udaljiti od izravne, konkretne, odnosno političke akcije. ${ }^{12}$ Zbog svega toga, smatra Kojève, ostavljeno je "plejadi intelektualaca svih odlika (koja je više ili manje rasprostranjena u vremenu i prostoru) na brigu da - na teoretskome planu - približi filozofske ideje političkoj realnosti”."13

Ovakvim stavom Kojève nedvojbeno izlazi iz polja ekskluzivne interpretacije Ksenofontova teksta te pri tome, $s$ nešto sasvim vidljive ironije, ulazi u suvremenost i njime ujedno referira i položaj europskog intelektualca unutar političke zbilje dvadesetoga stoljeća.

\section{marginalija Četvrta}

Spis Tiranija i mudrost Kojève završava stavkom: "Općenito, baš sama povijest preuzima na sebe da 'prosudi' djela državnika ili tiranina koje oni provode (svjesno ili ne) s obzirom na ideje filozofa koje su intelektualci prilagodili za primjenu." 14 Ulazeći u pitanja umijeća (: tèhne) tiranijskoga vladanja, pjesnik Simonid definiran je kao lik ${ }^{15}$ koji u Ksenofontovu dijalogu jasno pokazuje osnovnu strukturu svojega funkcioniranja. Ta je struktura

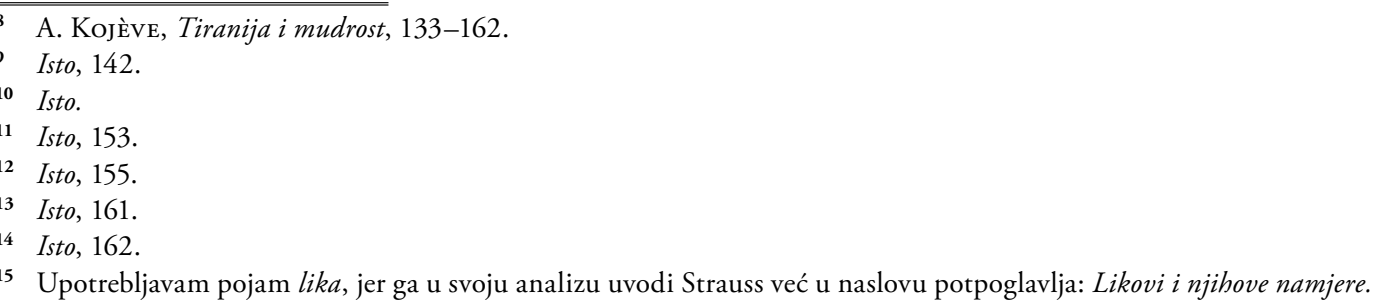


transformativna, ${ }^{16}$ jer je akterska. Ona je autorska, jer radi na učinak diskursa. Pri tome je ona i determinativna, jer samomu liku, kao takvomu, više pripada determinacija nego identitet.

Ulazeći u pitanja povijesnoga, pa, dakako, i društvenoga položaja intelektualca, Kojève - koji u Simonidu vidi lik "tipičnog intelektualca" - ustaljuje taj lik na mjestu "posrednika". To je lik, smatra Kojève, kojemu pripada da filozofske ideje "približi” političkoj realnosti. Štoviše, da ih "prilagodi za primjenu". Budući da se u teoriji, pa i u dnevnoj konverzaciji, često upotrebljava sintagma "lik intelektualca", a pojam lika susreće se danas već izuzetno učestalo i u slangu, na samu marginu ove marginalije dodao bih i jednu usputnost.

Lik u dijalogu, pa, naravno, i u drami, ima položaj sličan onomu koji su renesansni formalisti dodjeljivali subjektu. Naime, kako bi riješili svoje teške gramatičko-logičke zavrzlame s problemom subjekta, gramatičari XVI. stoljeća, primjerice, za izjavu: "Ja sam to" upotrebljavaju posebnu formulu: Ce suis je. ${ }^{17}$

Naime, ovim "redom oblika" pokazna zamjenica to (: ce) ovdje postaje subjekt iskaza. On je tako postavljenim "redom riječi” (: suis je) podržan i ujedno razdvojen od implicitnog subjekta $J a(: J e)$ glagolom biti (: suis = être). Sama forma ovog iskaza, smatraju stari gramatičari, takva je da ona "afirmira nešto od subjekta". ${ }^{18}$ Njegovu iskazivost, a ujedno i njegovu implicitnost.

U liku je uvijek, a moguće je kazati i oduvijek, neki implicitni subjekt. Kada se lik intelektualca "posrednika" pojavljuje u poziciji subjekta iskaza, tada nesumnjivo "afirmira" i nešto od nalogâ onog epohalnog, tj. "konstitutivnog" subjekta. U modernim vremenima, epohi "fenomenološkog"19 subjekta, liku intelektualca u ulozi "posrednika" sve više i sve češće konkurira lik intelektualca koji je u ulozi "nekog" upletenog, odnosno "umiješanog" u "ono što ga se ne tiče". ${ }^{20}$

Premda, dakle, još od samih početaka intelektualac nastupa na planu koji primarno nije meditacijski nego je medijacijski, počelo se tada dovršavati razdoblje, a u kojemu su, kako to duhovito formulira Sartre, "unuci filozofa postali intelektualci" (: les petit-fils des philosophes sont devenues les intellectueles). ${ }^{21}$ Može se, doista, reći da je danas riječ o jednome "modelu koji istječe" (H.-P. Müller).

\section{marginalija Peta}

Sve u svemu, "misija” intelektualca nedvojbeno podliježe Müllerovu pitanju: "Čemu (još) intelektualci?” To radikalno pitanje, međutim, ne znači danas više od jednog retoričkog pitanja.

\footnotetext{
16 Ovdje se prvenstveno oslanjam na analizu agregata elemenata, odnosno zakonâ sklopa same strukture na osnovi postavki Jeana Piageta. Usp. Jean Piaget, Le structuralisme, Pariz 1970.

17 Iulii Caesaris Scaligeri, De causis linguae latinae, libri tredecim, 1540. Citirano prema Julia Kristeva, Polylogue, Pariz 1977., 244.

18 Isto, 245-269.

19 Koristim ovdje pojam iz Foucaultove osnovne podjele subjekata na konstitutivni i fenomenološki mišljeni Subjekt. Usp. Michel Foucault, Znanje i moć, Zagreb 1994., 194.

20 Stav, dakako, pripada poznatom Sartreovom izrijeku da je intelektualac "netko tko se miješa u ono što ga se ne tiče". Usp. Jean-Paul SARTre, Plaidoyer pour les intelllectuelles, Pariz 1972., 25.

21 Isto, 12.
} 
Ukoliko je lik intelektualca to koje ima svoju povijesnu biografiju, a koja uvijek iznova "afirmira" nešto s polja Subjekta: po nalozima epohalno "konstitutivnih" subjekata ili, pak, uz djelovanje "fenomenološkog" subjekta modernih vremena i njegove posebne formativne prirode, utoliko se i sada nalazimo u vremenu koje neosporno i značajno dopisuje njegovu biografiju. Možda je i misao te biografije danas postala "slaba", ali učestalo pitanje "zašto?" pretvara problem strukture intelektualnoga diskursa, $s$ obzirom na njegovu jučerašnju svezanost, ali i njegovu današnju vezanost uz "stanje" filozofije i uz "stanje" politike.

Tu je pitanje o tome "koji su izvori legitimiteta i autoriteta intelektualca" 22 ostalo primarno. Kažemo da je ostalo primarno ne samo zato jer se, u svoj svojoj ozbiljnosti, ono pojavilo i održalo od kraja devetnaestoga stoljeća (1894. - 1898.), već i zato jer je tijekom čitavoga turbulentnoga dvadesetog stoljeća dinamikom događaja u njemu pitanje legitimiteta i autoriteta intelektualca i njihova izvora stalno iznova bilo provocirano, ali je stalno iznova ostajalo kao pitanje.

Razdoblje modernih vremena razdoblje je u kojemu je - filozofijski i praktički - do kraja bila u-ozbiljena relacija: mišljenje - akcija. To je bilo ono razdoblje u kojemu je vladala krilatica: "Sve je politika." Politika koja je tada za veliki dio intelektualnoga svijeta važila za "neku vrstu teologije zamjene" (J. Bouvresse). ${ }^{23}$ To razdoblje izuzetno je snažno upisano i u Aronovu rečenicu: "Sartre je živio dramu moralista izgubljenog u džungli politike." ${ }^{24}$ Usput, Winock smatra da je upravo Foucault, pogotovo knjigom Nadzirati i kažnjavati, mogao nastaviti slijedom Sartreove političke angažiranosti. ${ }^{25}$ Moderna vremena završavaju nastupom, inicijativama i "sirenama" postmodernoga doba, koje objavljuje i "kraj filozofije”.

Prvenstveno načelima "dekonstrukcije" ono se hoće "otarasiti” subjekta koji u svojem transcendentalnom, "praznom identitetu" (M. Foucault) tijekom čitave povijesti pokriva, pa i prepokriva, čitavo njezino polje događajâ. Dakle, ususret intelektualcu, u vremenu postmoderne, moglo bi se reći, ide ono što Kristeva naziva le sujet destabilisé. ${ }^{26}$ Ovim pojmom ona $u$-jedno obuhvaća "poljuljanu" personalizaciju, ali i "poljuljanu" konstitutivnost subjekta.

Ovim, pak, neugodnim susretom kojim prolazi iza svojih ogledala, suvremeni je intelektualac doista ozbiljno "poljuljan" i $o$ svome liku i $o$ svome diskursu. Ali "poljuljan” je još i zbog toga jer mu ni današnje "stanje" filozofije, a ni politike baš nikako ne ide na ruku.

\section{marginalija Šesta}

Alain Badiou, na primjer, kaže da je filozofija danas “izgubila svoju auru”. Izgubila ju je zato jer daleko više pripada mnijenju negoli mišljenju. Najviše prostora za sebe pronašla je, naime, u žurnalizmu, u "javnim kozerijama” o svemu i svačemu.

\footnotetext{
22 Postavlja ga slijedom komentiranja stavova E. Saida, a u sažetku svojega izlaganja s Desničinih susreta 2013., Vladimir Gvozden. Pitanje o autoritetu suvremenog intelektualca postavlja u svojemu sažetku i Rastko Močnik. Usp. Desničini susreti 2013. Intelektualac danas. Program rada / sažeci izlaganja (ur. Drago Roksandić, Filip Šimetin Šegvić i Nikolina Šimetin Šegvić), Zagreb 2013., 25-26, 35.

23 Jacques Bouveresse, "Le philosophe, les médias et les intellectuels", Agone, 2009., br. 41-42, 225-243.

24 Raymond Aron, "Mon petit camarade" (http://www.lexpress.fr/culture/livre/mon-petit-camarade_486874.html).

25 Usp. Michel Winock, Le siècle des intellectueles, Pariz 1999.

26 Julia Kristeva, Pouvoir de l'horreur, Pariz 1980., 35.
} 
Reklo bi se: kao što je čitava jedna dominantna civilizacija mislilaca, ona helenska, $s$ vremenom nestala i postala agora trgovaca, tako je i misao o "kraju filozofije" sišla na kioske, ušla u markete i dućane. Kao roba na jesenjoj rasprodaji. Institucionalno: filozofija djeluje u ograničenome, sasvim suženome prostoru između drugih akademskih disciplina. U njemu "obamrla" filozofija, tvrdi Badiou, oscilira između "retorike korektnih iskaza" i historičarskog proučavanja vlastite povijesti. Iznutra: filozofija je $u$ sebe "ucijepila" sustavnu sumnju u ono za što je sposobna.

Badiou ne pripada teoretičarima postmoderne i inicijativama dekonstrukcije. Cilj njegovih spisa nije "prevladavanje metafizike na način dekonstrukcije". Badiou se izjašnjava protiv "prenemaganja" o kraju filozofije. Njegovo je osnovno usmjerenje "rekvalifikacija" i "rekonstrukcija" filozofije. Ususret takvu cilju Badiou filozofiju danas interpretira kao ono koje uzorkuje nove "predmete znanja". Kao ono "koje sebe proizvodi kao uzorak, političkog, poetskog itd.”. ${ }^{27}$ Dramskog.

U svome prizivu ontologije ${ }^{28}$ Badiou nastoji ući u "začudnu logiku" refleksivne strukture događaja. Događaj je jedan od središnjih pojmova njegove ontologije. Uz događaj vezuje i ponovno utemeljenje teorije subjekta. U pozadini Badiouove ontologije jest postavka o "neprekidnome postojanju filozofije".

\section{marginalija Sedma}

Sve je, dakle, tu na prenatrpanim tezgama suvremenosti. Komercijalizacija "obamrle" filozofije, "kraj filozofije" i "neprekidno postojanje" filozofije. Sve je to danas ponuđeno suvremenom intelektualcu da bi - svojom diskurzivnom praksom "verbalnih aproksimacija" 29 - upravo s problemima koji s tih tezgi dolaze radio, ako hoće, ono što može. No, on više nije lik koji radi to što se više ne može. Recimo, pokušava "prilagoditi" nešto od recentnih stanja filozofije ili filozofskih zamisli političkoj realnosti.

Budući da je marksizam, u svojemu kanonskom obliku, bio posljednja filozofija vezana uz vlastiti politički uvjet, jasno je da nakon toga više nema riječi o nečijem posredovanju filozofije i stanovita oblika vladanja. Tzv. marksistički intelektualac bio je u situaciji da se brine jedino o političkome uvjetu filozofije marksizma. Ali ne u posredovanju, nego u odgovornom "provođenju" njezine političke Ideje. Izvršavanju svojih partijskih "zadataka". Zbog toga je - za mnoge intelektualce na desnici, pa i na samoj ljevici - "kraj ideologije bio poruka nade". ${ }^{30}$

Međutim, nakon političke odgovornosti za Ideju - pa i s onim poznatim poststaljinističkim posljedicama glede te odgovornosti - dolazi vrijeme politike bazirane na odgovornosti, ali bez Ideje.

Zanimljivo je da je - vjerojatno s očekivanjem onih problemâ koji bi baš otuda mogli doći - španjolski parlament 1984. uputio poziv Habermasu, koji je potom u svojemu govoru u parlamentu istaknuo dvije stvari. To da je budućnost sasvim "negativno zaposjednu-

\footnotetext{
27 Oliver Feltham, Alain Badiou: live theory, London - New York 2008., 173.

28 Za Badioua matematika jest ontologija. "Matematika jest znanost bića kao bića, prezentacija nekonzistentne mnogostrukosti”, kaže u uvodu L'être et l'événement (Pariz 1988.).

29 Ova je sintagma Sartreova.

30 Michael Freeden, Političke ideologije, Zagreb 2006., 14.
} 
ta", ali i to da je "utopijska perspektiva upisana u politički djelotvornu povijesnu svijest" te da "utopijsko mišljenje izgleda ima zadaću otvoriti alternative djelovanja". Dakako, mimo svih terora poduzetih u ime raznih utopijskih nacrta ${ }^{31}$ ciji je cilj bio neka societas perfecta.

\section{marginalija Osma}

Budući da je ovdje bilo ponajviše riječi o "situiranju" intelektualca u procijep između filozofije i politike, nemoguće je zaobići onaj, zapravo, jedini relevantni primjer kojim u dvadesetome stoljeću jedan od najznačajnijih i najutjecajnijih filozofa vlastitu misao sam "posreduje" jednom političkom obliku vladanja i njegovim "rješenjima".

Radi se, naravno, o Martinu Heideggeru, to jest prvenstveno o njegovu rektorskom govoru u Freiburgu iz 1933. godine, a potom i onom Heideggerovu iskazu iz 1935. kojim Hitleru daje mjesto u "području polu-bogova" (: der Halb-Götter). O ovome "slučaju" postoji opsežna literatura, a polemike o njemu gotovo da su neprekidne. Zadnju - u Nouvel Observateuru od 20. lipnja 2013. godine - potpisuje J.-P. Faye. Pa i pored eklatantne podrške nacionalsocijalizmu - iz čije je partije relativno brzo izašao - mišljenja o razlozima te podrške među uvaženim su teoretičarima vrlo podijeljena.

Ukratko: jedni su odlučni u tome da se tu radi ne samo o velikoj Heideggerovoj "grešci" nego i o "krivnji" i "grijehu”. Drugi se prema tome, u svojim pristupima i analizama, nastoje postaviti drukčije, pa i sasvim drukčije. Kako se sama Heideggerova podrška nacizmu zbiva unutar tzv. srednje etape njegove filozofije, faze potvrđivanja heroizma povijesnosti, tako je, između ostalog, otvorena i ta mogućnost da njegov nacistički angažman "nije pitanje adekvatnosti, odnosno podudaranja njegove misli i političkog djelovanja", nego se nalazi u Heideggerovoj "nemogućnosti da razriješi teorijsku zavrzlamu u kojoj se našao". ${ }^{2}$ Tu da s prstima u politici "iznjedri projekt od ontološkog i sudbinskog značaja" (M. de Beistegui).

U svakom slučaju ovaj moderni passage en acte, naime: prijelaz filozofa s misli na čin, ni ovoga puta nije uspio. Međutim, brojni intelektualci žive od pitanja koja je, svojim složenim slučajem, za sobom ostavio. Ona su teorijska i položajna. Praktička i supstancijalna.

\section{marginalija Deveta}

Heidegger je sumnjao, premda neki umjereniji kažu da nije "zdušno branio", da je demokracija onaj politički poredak koji bi bio i najbolji, a s obzirom na intenzivni napredak moderne tehnologije i u samu njezinu bit. Demokracija je danas u Europi - smatra Žižek i slažem se - "zapravo, administrativni projekt". ${ }^{33}$ Može se reći još i to da se radi o projektu bez "ideološke strasti”.

\footnotetext{
31 Platon, Campanella, Saint-Simon: "utopije poretka”; More, Fourier: "oslobodilačke utopije”.

32 Vidi o tome iscrpni tekst Slavoja Žižeka pod naslovom "Zbog čega je Heidegger ispravno postupio 1933. godine", koji odmah ima i svoju "fusnotu": "Ali ipak na krivi način". Turda, 9/2008., br. 1-2, 237-281. 
Kako bismo ovdje izbjegli muke s problemom ideološke strasti, ali i ne samo zato, valjalo bi s punom ozbiljnošću razmotriti Rancièreov stav da je jedno od temeljnih pitanja naše suvremenosti: kako ujediniti politiku i ono političko?

\section{marginalija Deseta}

Frank Furedi odlučno tvrdi, a to i argumentira, da je došlo vrijeme prizemne imaginacije, odnosno vrijeme u kojemu je "politika ostala bez teksta". ${ }^{34}$ Kada, na primjer, Donald Sassoon raspravlja o socijalizmu u dvadesetome stoljeću i o mogućnostima njegova definiranja, on zatečen obiljem njegovih sasvim "heurističkih vrijednosti" izbjegava svaku definiciju socijalizma, a pribjegava stavu, gotovo dosjetci, da je "socijalizam ono što socijalisti čine". ${ }^{35}$

Ako bi o aktualnoj hrvatskoj politici bila riječ, tada bi se na osnovi glagola "činiti" dalo samo jedno zaključiti. Nakon što su svoje političke pozicije, u doba rađanja tuđmanovske države Hrvatske, i svoje ciljeve "deklarirali" konzervativci, liberali, socijaldemokrati, pa sada i laburisti, svi oni u čitavome razdoblju 1990. - 2013. programski posluju ponajviše kao prekupci političkih načela.

Konzervativci su, na primjer, prekupci socijaldemokratske ideje o socijalnoj državi. Obrnuto, pak, od poznate Hobhouseove napomene da liberalizam, ako želi preživjeti, treba učiti od socijalizma, socijaldemokracija u Hrvatskoj preživljava kao glavni prekupac osnovnih liberalističkih ideja i pragmi. Laburisti su tek nespretni prekupci sindikalnih, krajnje raspršenih, interesa i zahtjeva. Zbog takva vrtloga i politički vokabular - dakako, ne samo kod nas - iskazuje "tešku zbrku", takvu da se "javne osobe teško više mogu brinuti za jezik politike". ${ }^{36}$

Don Watson, teoretičar društva, tvrdi da je zapravo došlo do "raspada javnog jezika” te da politika već posvuda govori "upraviteljskim žargonom". To kod njega znači mehaniziranim diskursom koji "ukida potrebu za razmišljanjem". ${ }^{37}$

Tragom ove postavke, današnji intelektualac - ako hoće (ima volju) misliti o politici i njezinu diskursu - nalazi se, između ostaloga, u situaciji da razmišlja o nečemu što upravo ukida potrebu za razmišljanjem. Antikno, diderotovski, to bi se danas moglo zvati: paradoks o intelektualcu.

\section{marginalija Jedanaesta}

Dug je i opsežan rapprochement kulture i politike. Jedno od ranih političkih trojstava u oblikovanju tzv. Države nacije bio je trokut: narod - nacija - kultura. Tu kultura ima središnju važnost kao "temelj nacije, kao poduka narodu i kao glavno orude demokracije". ${ }^{38}$

\footnotetext{
$\overline{34}$ Frank Furedi, Politika straha, Zagreb 2008., 13.

35 Donald SAssoon, "Socijalizam u dvadesetom stoljeću: povijesna refleksija”, Političke ideologije (ur. Michael Freeden), Zagreb 2006., 76 .

36 F. Furedi, Politika straha, 13.

37 Don Watson, Death Sentence: The Decay of Public Languge, Sydney 2004., 8.

38 Evelyne Ritaine, Les stratèges de la culture, Pariz 1983., 26-78.
} 
Jakobinska politička strategija bila je "okupiti kulturom”. Na kraju, pak, devetnaestoga stoljeća kulturni imperativ bio je "otkriti narod njemu samome". Godine 1930. započinje se formirati politika čije su ideje vodilje - a u svrhu pune afirmacije pročišćenoga nacionalnog bića - Kulturvolk i Totalstadt. Međutim, kad spominjemo politiku nacionalsocijalizma koja hoće dodijeliti svjetsku ulogu njemačkom narodu kao "narodu kulture", valja istaknuti i pobunu francuskih intelektualaca (1936.) potaknutu upravo tim "projektom”, čiji je slogan bio: "Mi kontinuiramo Francusku!"

Gotovo da ovdje i ne treba spominjati Rusiju 1918. i vrijeme proletkulta te dugotrajnu politiku i praksu socrealizma u svijetu socijalizma. Samo jedan stavak Lenjinova članka "Partijske organizacije i partijska literatura" već je dovoljan da se vidi ono o čemu se i kako se tu radilo. Preporučuje se, na primjer, da "književni dio partijske stvari proletarijata ne treba biti šablonski identificiran $s$ drugim dijelovima partijske stvari proletarijata". ${ }^{39}$

Zatim dolazi Država s idejom "animiranja zajednice", pa onda i Država u dvije funkcije: "kulturnog planera" i "društvenog terapeuta". Kultura je kroz povijest postajala, samom prirodom svoje ili silom političke stvari, reklo bi se, nezaobilazni "faktor" u izgradnji Države, dok je sada ona toga sasvim razriješena. Razriješena tako da jedino kulturna industrija ima mjesto u interesima Države. Kultura supstancijalno - dakle: njezino imaginarno koje je oduvijek upogonjeno - samoj politici više nije ničemu i ni za što.

Stoji činjenica da se Država danas "povlači”, ali ne politički planirano (što je bila osnovna ideja "tačerizma"), već i zbog ozbiljna nedostatka političke imaginacije. Dakako, nikako ne samo zbog njezine prizemnosti, već i zato jer svijet ekonomije i financija, jer diktat tzv. slobodnog tržišta - slažu se u tome i kritičari i zagovornici kapitalizma - daje "vrlo malo mjesta za učinkovito političko djelovanje". ${ }^{40}$

\section{marginalija Dvanaesta}

Ukoliko je danas "politika ostala bez teksta", utoliko je nužno upozoriti na jaku Badiouovu platonističku postavku da je "politička invencija sama tekstura misli". ${ }^{41}$ U 9. knjizi Platonove Države riječ je, naime, upravo o tome da je politika uvjet mišljenja.

Pjesnik, "učeni čovjek" Simonid s Hijerontom, tiraninom, razgovora pod tim uvjetom. Ako je on "tipični intelektualac" najavljen iz onoga vremena, "zašto?" onda brojne - možda atipične? - suvremene intelektualce stavljati u sumnju kad oni taj uvjet mišljenja, neosporno je, misle. To uglavnom čine $i z$ onih problemâ koje svakodnevno otvara nedostatak političke invencije. Što to ne čine današnji političari vjerojatno potječe iz istog, ovdje navedenog, a sada već prastarog razloga: jer im "vladanje uzima sve vrijeme jednog čovjeka".

\footnotetext{
39 Boris ZIHERL, Umetnost $i$ idejnost, Beograd 1957.

40 F. Furedi, Politika straha, 25-27.

41 Alain BADIOU, Manifest za filozofiju, Zagreb 2001., 15.
} 


\section{umjesto zaključka: marginalija Trinaesta}

"Bez obzira na to kakva bila naša posvećenost dekonstrukciji metafizike i borbi za nove oblike mišljenja i djelovanja, (...) mi i dalje nastavljamo živjeti unutar metafizičkog konteksta..." kaže de Beistegui. ${ }^{42}$ U kontekstu te borbe za nove oblike mišljenja i djelovanja, a istodobno života unutar metafizičkog konteksta, intelektualac i opet ima svoju priliku. Prvenstveno zato što je lik koji je - onomad posredujući, a jučer sudjelujući - izgradio vlastitu biografiju na svojemu coagitare. ${ }^{43}$ Mogućnosti da "skupa protrese" strane koje se opiru dijalogu.

Osim toga: intelektualca - a nakon racionalističkog, još ne ražalovanog Ego sum - na površini same suvremenosti još uvijek održavaju jake snage modernističkoga Ecce ego.

\section{$\cos$}

\section{The Intellectual: Rumours of the Subject (Twelve Marginalia, With the Thirteenth INSTEAD OF A CONCLUSION)}

In Xenophon's work Hiero, the poet Simonides is the first in Greek philosophy to discuss an issue raised by a ruler in a moment of "leisure", of how to "improve his rule". Simonides is the first non-philosopher entering a discussion formerly reserved only for a dialogue between the philosopher and the ruler. By entering it, Kojève states, the poet appears as an intermediary figure between them, as an intellectual, who attempts to mediate the language of thoughts to the language of power. He is an intermediary subject. In today's terms it could be said that he is endeavouring towards the permeability of discourse. In the age of postmodernism, the position of the subject is a precarious one. Some philosophers announce the "death of the subject" and its vanishind, others speak of its "weakness", claiming it is a category which no longer has anything to say, or to offer. Today, philosophers mostly constitute postphilosophies. The biographies of the intellectuals, on the other hand, remain what they used to be a long time ago. They represent the rumours of the subject, of its existence rather than non-existence, of its death taking a toll on everyone, of its weakness being its strength...

Keywords: tyrant, poet, philosopher, intellectual, master of discourse, coagitare

\section{$\cos$}

\section{Literatura}

Raymond Aron, "Mon petit camarade" (http://www.lexpress.fr/culture/livre/mon-petit-camarade_486874.html).

Alain BADIOU, L'être et l'événement, Pariz 1988.

Alain BAdiou, Manifest za filozofiju, Zagreb 2001.

Miguel de Beistegui, The New Heidegger, London 2005.

\footnotetext{
$\overline{42}$ Miguel de Beistegui, The New Heidegger, London 2005., 185.

43 Jozo Marević i dr., Latinsko-hrvatski enciklopedijski rječnik, sv. 1, Zagreb 2000., 491.
} 
Jacques Bouveresse, "Le philosophe, les médias et les intellectuels”, Agone, 2009., br. 41-42, 225-243.

Oliver Feltham, Alain Badiou: live theory, London - New York 2008.

Michel Foucault, L'ordre du discours, Pariz 1971.

Frank Furedi, Politika straha, Zagreb 2008.

Martin Heidegger, "Parmenides”, Gesamtausgabe, knj. 54, Frankfurt am Main 1982.

Julia Kristeva, Polylogue, Pariz 1977.

Julia Kristeva, Pouvoir de l'horreur, Pariz 1980.

Jozo Marević i dr., Latinsko-hrvatski enciklopedijski rječnik, sv. 1, Zagreb 2000.

Jean Piaget, Le structuralisme, Pariz 1970.

Evelyne Ritaine, Les stratèges de la culture, Pariz 1983.

Drago Roksandić - Filip ŠImetin ŠEgVIĆ - Nikolina ŠImetin Š́tegvić (ur.), Desničini susreti 2013. Intelektualac danas. Program rada / sažeci izlaganja, Zagreb 2013.

Jean-Paul SArtre, Plaidoyer pour les intelllectuelles, Pariz 1972.

Donald SAssoon, "Socijalizam u dvadesetom stoljeću: povijesna refleksija” Političke ideologije (ur. Michael Freeden), Zagreb 2006., 75-99.

Leo Strauss, O tiraniji - Ksenofont, Hijeront ili o tiraninu - Alexandre Kojève, Tiranija $i$ mudrost, Zagreb 1980.

Michel Winock, Le siècle des intellectueles, Pariz 1999.

Boris ZiHerL, Umetnost $i$ idejnost, Beograd 1957.

Slavoj ŽıžEK, “Zbog čega je Heidegger ispravno postupio 1933. godine”, Tvrda, 9/2008., br. 1-2, 237-281. 